\title{
The VL2-Spoken Language Phonological Awareness (VL2-SLPA) Measure
}

\author{
M. Diane Clark \\ Gallaudet University, Washington, USA \\ Email:diane.clark@gallaudet.edu
}

Received July 28 ${ }^{\text {th }}, 2012$; revised August $23^{\text {rd }}, 2012$; accepted September $20^{\text {th }}, 2012$

\begin{abstract}
Tests of phonological awareness have been developed for spoken languages that require spoken responses. For many deaf individuals, spoken measures of phonological awareness (PA) are not appropriate, as these deaf individuals do not use any spoken language or their oral language is rated as low on levels of aural comprehension. Given the need to have accessible measures of spoken language PA for deaf children, the VL2 Spoken Language Phonological Awareness Measure (VL2-SLPA) was developed. The VL2-SLPA can also determine if participants use a phonological code or an orthographic code to identify the two pictures that have the same first or last "sound". The VL2-SLPA showed strong convergent validity to the Phoneme Detection Test, another measure developed for deaf individuals, which does not require a verbal response.
\end{abstract}

Keywords: Phonological Awareness; Measure; Deaf

The term phonological comes from the Greek word phone, which means voice or sound (Wagner, Torgesen, \& Rashotte, 1999). Interestingly, phonemes are recognized along category boundaries rather than on acoustic similarity (Liberman, Harris, Hoffman, \& Griffith, 1957). Here two stimuli that have the similar perceptual or acoustic differences are not perceived as different phonemes unless they cross a categorical boundary. Therefore, phonemes are not perceived along a continuous dimension but are perceived as discrete units. This discrimination allows individuals using aural/oral language to segment auditory stimuli into language specific phonemes, adjusting for spoken variation in individual speakers. Decoding of words into their individual phonemes is based on specific articulatory movements, depending on the placement of the tongue in the mouth the position of the lips, whether the mouth is closed or open, and whether the vocal cords are vibrating (Wagner et al., 1999). Therefore, phonemes represent differences in speech sounds that signal differences in meaning.

Phonological awareness (PA) includes not only the sounds of a language but also how words rhyme. PA leads to the awareness that sentences can be broken down into words, syllables, and their corresponding sounds. These skills develop throughout the late preschool period and are tested by a child's ability to detect rhyme and alliteration or the use of similar consonants. PA also includes being able to identify words that start and end with the same sounds as well as segmenting words into their corresponding phonemes. Blending of new sounds is often tested when looking at children's PA.

The reason that PA is considered to be a necessary skill is that is relates to the alphabetic principle (Chard \& Dickson, 1999) that allows students to understand the internal structure of words so that they can benefit from formal reading instruc-

\footnotetext{
${ }^{*}$ This version of the VL2-SLPA measure is in English. In the International Reading Project, four other parallel versions were also created; one in Arabic, German, Hebrew, and Turkish.
}

tion. The University of Oregon's Center on Teaching and Learning ("What is the," 2009) defines alphabetic understanding as the knowledge that "words are composed of letters that represent sounds" (para 1). This concept is linked to phonological recoding, which is defined as "using systematic relationships between letters and phonemes (letter-sound correspondence) to retrieve the pronunciation of an unknown printed string or to spell words" (para 2). Then phonological processing refers to the use of this information that translates the sounds of oral language into the comprehension of written language.

Mastery of phonological awareness is seen as important to the development of reading, writing, and spelling for languages that use the alphabetic principle (Wagner \& Torgesen, 1987). Studies have found a casual influence between the development of phonological processing abilities and the acquisition of word-level reading skills (Perfetti, Beck, Bell, \& Hughes, 1987) and a deficit in phonological abilities is viewed as a the reason for reading disabilities (Shankweiler \& Liberman, 1989; Stanovich \& Siegel, 1994).

Deaf education also tends to focus on phonological knowledge as a necessary skill for skilled reading (e.g., Paul, Wang, Trezek, \& Luckner, 2009). Paul et al. state, "Phonology cannot simply be abandoned even for children with limited or no access to it" (p. 348) and "Again, we contend that phonological awareness is necessary, but not sufficient, for reading comprehension" (p. 350). Based on these ideas, both cued speech and visual phonics have been used with deaf children. Cued speech is a system that allows all of the phonemes of a language to be visual to a deaf child while visual phonics is a classroom based phonics curriculum that helps deaf children learn to read English. Here the explicit assumption is that having access to the spoken phonemes of the language through a visual medium will allow the development of skilled reading for deaf children (LaSasso, Colin, \& Leybaert, 2011). 


\section{Tests of Phonological Awareness for Aural/Oral Languages}

Tests of phonological awareness have been developed for spoken language. These measures require a spoken response in response to the stimulus. These tests include subtests of the Woodcock Johnson (Woodcock, McGrew, \& Mather, 2007) as well as the Test of Phonological Awareness (TOPA; www. proedinc.com/customer/productview.aspx?ID=2844). Two additional tests used with spoken language include The Phonological Awareness Test (PAT 2) (www.linguisystem.com/ products/product/display?itemid=1049) and the Comprehensive Test of Phonological Processing (Wagner, Torgesen, \& Rashotte, 1999). These measures are easily administered to hearing individuals and provide information regarding the level of PA skills used by them.

For many deaf individuals, spoken measures for phonological awareness are not appropriate. Many deaf people do not use spoken language or their oral language is rated as low on levels of aural comprehension. Therefore, typical measures of PA that require spoken responses to tap this knowledge of spoken phonology may not reflect deaf individuals PA skills as the tester must make judgment calls as to whether the spoken response is accurate. Conrad (1979) reported that many deaf individuals have what has been referred to as inner speech, which functions like spoken phonological knowledge. Therefore, having measures of spoken PA are felt to be important in understanding the reading skills of deaf individuals.

Recently, a measure of spoken PA test was developed that does not require a verbal response. This test is called the Phoneme Detection Test (PDT; Koo, Crain, LaSasso, \& Eden, 2008) and is administered via computer, using 150 high frequency words. Participants are instructed to determine whether a word, presented visually on the computer, includes a specific phoneme (e.g. Does it have a $/ \mathrm{k} /$ ). Target phonemes include multiple or opaque orthographic to phonological correspondences (e.g. "c" maps to the phoneme /s/ in "cent" and /k/ in "call"). The PDT test has been shown to identify PA skills in deaf participants (Clark, Gilbert, \& Anderson, 2011; Koo et al., 2008). Koo et al. found that signing deaf participants were less accurate than deaf participants who were either oral or used cued speech, i.e., those who had grown up with a focus on spoken phonology. Clark et al. found a wide range of PA skills, ranging from one percent correct to 99 percent correct. In addition, Clark et al. found no correlation between PA scores and reading skills. Given these results, the PDT provides important information about deaf adults spoken language PA skills as both Clark et al. and Koo et al. used young adults.

Because PA has been related to young children's reading development, it becomes necessary to have tests that can be used with younger participants. The Koo et al. (2008) PDT test has not been used with children and given the length of the test may not be appropriate for this age group. Given the need to have an accessible measures of spoken language PA for deaf children that does not require a verbal response, the VL2 Spoken Language Phonological Awareness Measure (VL2-SLPA) was developed (Miller, Kargin, \& Clark, 2010) ${ }^{1}$ for use in an International Reading Study with children. The measure includes 12 trials; six testing awareness of initial phonemes and six testing final phonemes. All words are from a third-grade corpus. Each trial has four pictures. The four pictures include a

\footnotetext{
${ }^{1}$ The VL2-SLPA is available from diane.clark@gallaudet.edu.
}

distracter, two items that are a phonological match on either the initial or final phoneme, and two items that match orthographically.

In Figure 1 (a sample item), the pictures of a knot and a gnome are phonological matches while the pictures of a gnome and a goat are an orthographic match. The star is the distracter. All pictures are color drawings. Participants are provided the stimuli in computer format using PowerPoint. Four practice trails are included with feedback to be sure that participants understand the task.

The research question for this study focused on determining if the VL2-SLPA could be used as a quick measure of PA with adults. The PDT was therefore compared to the VL2-SLPA to determine if convergent validity could be established.

\section{Method}

\section{Participants}

The study included 56 college students from a convenience sample at an ASL/English bilingual liberal arts college on the east coast for deaf and hard of hearing students. The sample included seven men (mean age $=21.3$ years) and 43 woman (mean age $=23.5$ years). Six participants did not include their sex on the background questionnaire. English or ASL was the native language of the participants and they all had a hearing loss of above $70 \mathrm{db}$. The majority of the participants reported that their language preference is American Sign Language $(\mathrm{n}=$ 47). In addition, the majority of the participants $(n=44)$ were born deaf. Therefore, this sample is similar to the deaf signing group in the Koo et al., (2008) study.

\section{Procedure}

Testing took about one hour. Participants were paid 20 dollars an hour for their time. Participants completed three measures that are reported here.

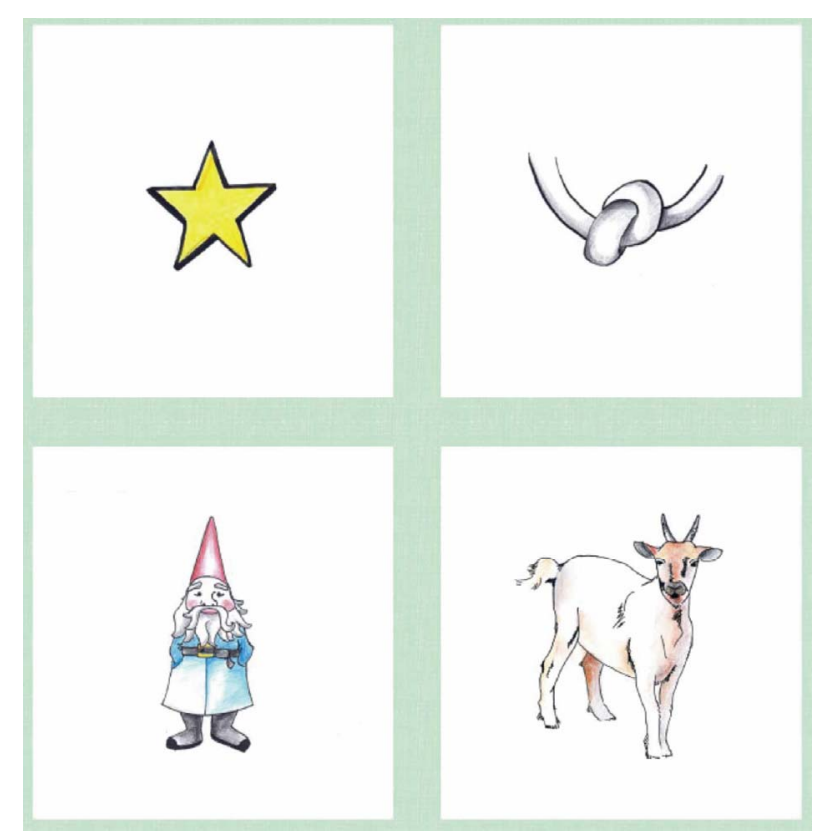

Figure 1.

Sample item from the VL2-SLPA. 


\section{VL2 Background Questionnaire}

The approved VL2 Background Questionnaire was administered to all participants. This measure collected information on language preference and information related to their hearing loss.

\section{PDT}

The Koo et al., (2008) Phoneme Detection Test was administered to all participants. The test, includes a set of four practice trials to show that phonemic units, rather than orthographic units, are the focus of each trial. Participants were instructed to respond as fast and as accurately as possible. Responses are recorded by pressing 1 on the keyboard if the word includes the target phoneme or 2 if it does not have the target phoneme. Five blocks of 30 items are included. Half of the items have the target phoneme in either initial, medial, or final position within the word while the other half of the items was foils. Order of blocks is counterbalanced across participants.

\section{VL2-SLPA}

All participants completed the Miller et al. (2010) picture measure of PA. Recognition of each picture was tested prior to the start of the test to insure that participants were familiar with the words. If a picture was not named correctly, participants were retested on items that they had gotten incorrect. Next, they were instructed to pick the two pictures where the initial (final) sound was the same. Two sample items were presented, two for initial sounds and two for final sounds. If participants did not select the two phonologically matching pictures, they were told which two were correct and why. Responses were recorded on a separate coding form that recorded which two pictures were selected. Each response was timed using a stopwatch and the reaction time was recorded on the coding form. After completing each trial, participants pressed the space bar to continue to the next item.

\section{Results}

Percentage scores were used to compare the PDT and the VL2-SLPA measures.

The range of the PDT was from $2 \%$ to $94 \%$ correct, with an average of $61 \%$ correct per block and a standard deviation of 15.1 per block (raw mean per block $=18.7$, SD 3.7). The range of the VL2-SLPA was from $25 \%$ to $100 \%$ correct, with an average of $54.8 \%$ correct and a standard deviation of $18.5 \%$ (raw mean $=6.6, \mathrm{SD}=2.2$ ). The correlation between the PDT and the VL2-SLPA was $r=.54$, demonstrating a strong correlation between these two measures (Cohen, 1988.) Using a dependent $\mathrm{t}$ test, the PDT was found to have a higher percentage correct than the VL2-SLPA, t $(41)=-2.34, p=.02$.

On the VL2-SLPA, participants could select either a phonological match or an orthographic match. Using a dependent $t$ test with the raw scores on the VL2-SLPA, it was found that participants were more likely to select the phonological match for initial phonemes (mean $=2.57, \mathrm{SD}=1.10)$ than the orthographic match $($ mean $=1.94, \mathrm{SD}=.85), \mathrm{t}(46)=2.72, p=.009$. They were also more likely to select the phonological match for final phonemes $($ mean $=3.27, \mathrm{SD}=1.21)$ than the orthographic match $($ mean $=1.90, \mathrm{SD}=.1 .00), \mathrm{t}(40)=4.38, p=.000$.

\section{Discussion}

The VL2-SLPA showed strong convergent validity with the
PDT. The strong correlation demonstrates that both measures can provide an indication of a deaf participant's PA without a verbal response. The difference between the PDT and the VL2SLPA can be explained by the difference in the number of responses for each measure. Participants on the PDT have a 50/50 chance of getting the correct response, even if they are guessing. The VL2-SLPA has four response choices, which reduces the probability of getting the correct response on a simple guess. In addition, the VL2-SLPA can evaluate not only PA but gives participants an option to select an orthographic choice. These two sub-scores may allow researchers to identify participants who prefer an orthographic response.

Watching participants in this study was painful as they struggled to pick the correct match. Hearing pilot participants took about five minutes to complete this task, remember it is only 12 items. Deaf participants often took 20 minutes to complete this task. The importance placed on phonology is clearly understood by deaf individuals and they wanted to do well on this task. One might hypothesize that they would think, "whatever-I will just guess". This guessing strategy was clearly not the case. Some participants could easily do the task and scored $100 \%$ correct. Others struggled and still were unable to select the correct item.

These participants did not substitute an orthographic strategy for a phonological strategy. They understood the goal of the task, obtaining an overall average of a bit over $50 \%$ of the items correct. Currently, this VL2-SLPA measure is being used to collect data on younger readers in the VL2 International Reading Project and it will be interesting to see if they select an orthographic strategy in this task. Bélanger, Baum, and Mayberry (2011) found that only skilled deaf readers used a phonological code while less skilled deaf readers used an orthographic code. The participants in this study tend to be skilled deaf readers as they are college students. Therefore, the results of the ongoing study with younger and less skilled deaf readers will help to answer this question.

Future research can compare results on the VL2-SLPA to more traditional measures like the TOPA or PAT 2. If deaf phonological users show higher levels of PA on the VL2-SLPA than the tests that typically require spoken responses, it will support the ideas of Conrad (1979) that skilled deaf readers have inner speech that they used to decode written texts even if their spoken responses may not be showing this effect. One would need to select these participants based on the PA abilities rather than their reading skills, as we have evidence that skilled deaf readers may or may not use spoken language phonology (Allen, Clark, del Giudice, Koo, Lieberman, Mayberry, \& Miller, 2009; Bélanger, Baum, \& Mayberry, 2011, Clark, Gilbert, \& Anderson, 2011; Miller \& Clark, 2011).

The VL2-SLPA measure can be used to evaluate spoken language phonology for anyone, hearing or deaf - adult or child. Future analysis of the VL2 International Reading Project will provide data on this comparison, with information on 3rd and 4th graders, 6th and 7th graders, and 9th and 10th graders who are both hearing and deaf. The measure is easy to administer and can be obtained through the VL2 Toolkit Project.

\section{Acknowledgements}

This work was partially supported by National Science Foundation under grant number SBE-1041725 and from a Small Grant to Jessica Feldman from the Gallaudet Research 
Institute. Part of this work was presented at the Annual Meeting of the Association for Psychological Science, Washington, D. C., by Jessica Feldman as part of her undergraduate research internship. We would like to thank Selina Agyen for her help with this project as well as the other VL2 graduate assistants and the research participants.

\section{REFERENCES}

Allen, T. E., Clark, M. D., del Giudice, A. Koo, D., Lieberman, A., Mayberry, R., \& Miller, P. (2009). Phonology and reading: A response to Wang, Trezek, Luckner, and Paul. American Annuals of the Deaf, 154, 338-345. doi:10.1353/aad.0.0109

Bélanger, N. N., \& Baum, S. R., \& Mayberry, R. I. (2011). Reading difficulties in adult deaf readers of French: Phonological codes, not quilty! Scientific Studies of Reading, 1-23.

Chard, D. J., \& Dickson, S. V. (1999). Phonological awareness: Instructional and assessment guidelines. Intervention in School and Clinic, 34, 261-270. doi:10.1177/105345129903400502

Clark, M. D., Gilbert, G. L., \& Anderson, M. L. (2011). Morphological knowledge and decoding skills in deaf readers. Psychology, 2, 109116. doi:10.4236/psych.2011.22018

Cohen, J. (1988). Statistical power analysis for the behavioral sciences. (2nd ed.). Mahwah, NJ: Lawrence Erlbaum Associates.

Conrad, R. (1979). The deaf school child. London: Harper and Row.

Koo, D., Crain, K., LaSasso, C., \& Eden, G. F. (2008). Awareness and short-term memory in hearing and deaf individuals of different communication backgrounds. Annuals of the New York Academy of Science, 1145, 83-99. doi:10.1196/annals.1416.025

LaSasso, C., Colin, S., \& Leybaert, J. (2011). Cued Speech for deaf children's mastery of the alphabetic principle. In C. LaSasso, K. Crain, \& J. Leybaert (Eds.), Cued Speech and Cued Language for
Deaf and Hard of Hearing Children (pp. 245-284). San Diego, CA: Plural Publications Inc.

Liberman, A. M., Harris, K. S., Hoffman, H., \& Griffith, B. (1957). The discrimination of speech sounds within and across phoneme boundaries. Journal of Experimental Psychology, 52, 127-137. doi: $10.1037 / \mathrm{h} 0041240$

Miller, P., \& Clark, M. D. (2011). Phonemic awareness is not necessary to become a skilled deaf reader. Journal of Developmental and Physical Disabilities. doi:10.1007/s10882-011-9246-0

Miller, P., Kargin, T., \& Clark, M. D. (2010). The VL2 Spoken Language Phonological Awareness (VL2-SLPA) Measure. Washington: Gallaudet University.

Paul, P. V., Wang, Y., Trezek, B. J., \& Luckner, J. L. (2009). Phonology is necessary, but not sufficient: A rejoinder. American Annals of the Deaf, 152, 346-356. doi:10.1353/aad.0.0110

Perfetti, C. A., Beck, I., Bell, L. C., \& Hughes, C. (1987). Phonemic knowledge and learning to read are reciprocal: A longitudinal study of first grade children. Merrill-Palmer Quarterly, 33, 283-319.

Shankweiler, D., \& Liberman, I. (1989). Phonology and reading disability. IARLD Monograph, No. 6. Ann Arbor, MI: University Press.

Stanovich, K. E., \& Siegel, L. S. (1987). The phenotypic performance profile of reading-disabled children: A regression-based test of the phonological-core variable-difference model. Journal of Educational Psychology, 86, 24-53. doi:10.1037/0022-0663.86.1.24

Wagner, R. K., \& Torgesen, J. K. (1987). The nature of phonological processing and its causal role in the acquisition of reading skills. Psychological Bulletin, 101, 192-212. doi:10.1037/0033-2909.101.2.192

Wagner, R. K, Torgesen, J. K., \& Rashotte, C. A. (1999). The comprehensive test of phonological processing: Examiner's manual. Austin, TX: pro-ed.

Woodcock, R. W., McGrew, K. S., \& Mather, N. (2007). Woodcock Johnson III. Rolling Meadows, IL: Riverside Publishing Company. 